\title{
Kontrollü Overyan Stimülasyon Protokollerinde rLH Tedaviye Eklenmeli mi?
}

\author{
Should rLH Be Added to the Treatment in Controlled Ovarian Stimulation \\ Protocols? \\ Özcan BUDAK ${ }^{1} \mathbb{D}$, Mehmet Sühha BOSTANCl ${ }^{2}$ (D) , Songül DOĞANAY ${ }^{3}$ (D) \\ Nermin AKDEMIR ${ }^{2}$ (D), Arif Serhan CEVRIOĞLU ${ }^{2}$ (D)
}

\author{
${ }^{1}$ Sakarya Üniversitesi Tıp Fakültesi Histoloji-Embriyoloji Anabilim Dalı, Sakarya, TÜRKIYE \\ ${ }^{2}$ Sakarya Üniversitesi Tıp Fakültesi Kadın Hastalıkları ve Doğum Anabilim Dalı, Sakarya, TÜRKiYE \\ ${ }^{3}$ Sakarya Üniversitesi Tıp Fakültesi Fizyoloji Anabilim Dalı, Sakarya, TÜRKiYE
}

Öz.

Amaç: Kontrollü overyan hiper stimülasyon (KOH), in vitro fertilizasyon (IVF) tedavilerinin temeli durumundadır. Folükül stimüle edici hormon (FSH), antral folliküllerin büyümesinin temel düzenleyicisi iken, lüteinleștirici hormon (LH) da steroidogenezin desteklenmesinde etkindir. $\mathrm{LH}$ overyan stimülasyonda etkili olmasına rağmen, literatürde $\mathrm{KOH}^{\prime}$ a $\mathbf{L H}$ takviyesi eklenmesi hakkında net bir görüs birliği bulunmamaktadır. Bizde çalısmamızda kendi kliniğimizdeki olgularda;ín vitro fertilizasyon/intrasitoplazmik sperm enjeksiyonu (IVF/ICSI) uygulanan kadınlarda ,over stimülasyonu için, rekombinant luteinize edici hormonun $(\mathrm{rLH})$ ve rekombinant folikül uyarıı hormon (rFSH) ile tek başına rFSH kullanımının etkinliğini ve güvenliğini retrospektif olarak karşılaştırmayı amaçladık.

Materyal ve Metod: Çalışmamıza Sakarya Üniversitesi Eğitim ve Araştırma Hastanesi Tüp Bebek Merkezinde 2019-2020 yılları arasında tedavi gören 89 infertil çift dahil edildi. IVF tedavisine alınan normal over fonksiyonuna sahip hastaların verileri incelendi. KOH için; yalnızca, $\mathrm{rFSH}$ (Gonal-F) kullanan ve rFSH (Gonal-F) ve r-LH (Luveris) ‘ ı birlikte kullanılan hastaların sonuçları retrospektif olarak karşılaştırıldı. Ayrıca 35 yaş üstü ve 35 yaş altı hasta grupları için rFSH, rFSH+rLH stimülasyon sonuçları alt grup olarak değerlendirildi. Çalışmamızda toplam oosit sayıIs, toplam metafaz II(MII) sayıları ve gebelik oranları da karşılaştıııldı. Bulgular: Çalışmaya dahil olan seksen dokuz hastanın, 40' । rFSH (Grup 1) ve 49 da rFSH + rLH (Grup 2) grubundaydı. Tüm yaş grupları içinde değerlendirildiğinde, gruplar arasında total gonadotropin miktarı ve stimülasyon gün sayısı dışında istatistiksel fark görülen başka bir parametre izlenmedi.35 yaş üstü ve 35 yaş altı hastalar ayrı ayrı değerlendirildiğinde; oosit sayısı,toplam MII oositler, Grade I embriyo sayısı ve gebelik oranları bakımından, her iki grup arasında istatistiksel olarak anlamlı farklılık izlenmedi.

Sonuç: 35 yaş ve üstü over reservi normal hasta grubunda r-LH ilave edilen ve edilmeyen stimülasyon protokolleri arasında, sonuçlar $r$-LH grubunda daha olumlu görülse de, istatistiksel olarak anlamlı fark görülmedi. Çalışmamızda, IVF ICSI uygulamalarında kullanılan $\mathrm{KOH}$ protokollerine, $r$ - $\mathrm{LH}$ ilavesinin tüm yaş gruplarında tedavi başarısı üzerinde etkinliğinin bulunmadığı görüldü. Bununla birlikte, hasta sayısının daha fazla olduğu çalışmaların yapılması gerektiğini kanaatindeyiz.

Anahtar Kelimeler: rLH, İn Vitro Fertilizasyon, Kontrollü Ovaryen Hiper Stimülasyon

Abstract

Background: Controlled ovarian hyperstimulation $(\mathrm{KOH})$ is the basis of in vitro fertilization (IVF) treatments. At the same time, follicle-stimulating hormone (FSH) is the primary regulator of the growth of antral follicles. Luteinizing hormone (LH) is also effective in supporting steroidogenesis. Although LH is effective in ovarian stimulation, there is no clear consensus in the literature about adding $\mathrm{LH}$ supplementation to $\mathrm{KOH}$. In our study, we aimed to compare to retrospectively analyzed the efficacy and safety of using recombinant luteinizing hormone $(r \mathrm{LH})$ and recombinant follicle-stimulating hormone $(\mathrm{rFSH})$ and $\mathrm{rFSH}$ alone for ovarian

stimulation in women undergoing in vitro fertilization/intracytoplasmic sperm injection (IVF/ICSI) in cases in our clinic Materials and Methods: 89 infertile couples treated at Sakarya University Training and Research Hospital IVF Center between 2019-2020 included in our study. The data of patients with a normal ovarian function who treated with IVF were analyzed. For $\mathrm{KOH}$, the results of patients who used rFSH (Gonal-F) alone and rFSH (Gonal-F) and r-LH (Luveris) together were compared retrospectively. In addition, $\mathrm{rFSH}, \mathrm{rFSH}+\mathrm{rLH}$ stimulation results were evaluated as a subgroup for the patient groups over 35 years old and under 35 years old. Our study also compared the total number of oocytes, total metaphase II (MII) numbers, and pregnancy rates.

Results: Of the 89 patients included in the study, 40 were in the rFSH group (Group 1), and 49 were in the rFSH $+\mathrm{rLH}(\mathrm{Group} 2)$ group. No statistical difference was observed between the groups except the total gonadotropin amount and stimulation days When evaluated within all age groups. When the patients over 35 years old and under 35 years old assessed separately; There was no statistically significant difference between the two groups in terms of oocytes count, total MII oocytes, Grade I embryo count and clinical pregnancy rates.

Conclusion: Although the results were more positive in the $\mathrm{r}$-LH group, we could not detect

a statistically significant difference between the stimulation protocols with and without $\mathrm{r}$-LH in the $35-40$ age range, a regular patient population with ovarian reserve. As in our study, we were adding $\mathrm{r}$ - $\mathrm{LH}$ to the controlled ovarian stimulation protocols used in IVF_ICSI applications does not seem to affect treatment success in women of all age groups. However, we believe that studies with a more significant number of patients should be conducted.

Key Words: rLH, In Vitro Fertilization, Controlled Ovarian Hyperstimulation
Sorumlu Yazar/Corresponding Author

Dr. Özcan BUDAK

Sakarya Üniversitesi Tıp Fakültesi

Histoloji-Embriyoloji Anabilim Dalı, Sakarya/TÜRKIYE

E-mail: ozcanbudak@sakarya.edu.tr Geliş tarihi / Received: 08.06.2021 Kabul tarihi / Accepted: 08.07.2021 DOI: $10.35440 /$ hutfd.949385 


\section{Giriş}

İki hücre-iki gonadotropin hipotezine göre gonadotropin eksikliği olan anovulatuar kadınlarda ovaryan steroidogenez için FSH ve LH gereklidir. Folliküler faz boyunca yeterli folüküler estardiol $\left(E_{2}\right)$ üretimi, oosit maturasyonunun $t$ mamlanması ve endometriyumda gelişimin sağlanması için LH desteğine ihtiyaç vardır. Ancak normogonadotrpik kadınlarda ovaryan stimulasyon için LH gerekliliği tartı malıdır. FSH ile stimüle sikluslarda LH eklentisinin folikül gelişimi arttırması ve böylece tedavi süresini kısaltması açısından avantaj sunabilir(1).

$\mathrm{KOH}$, IVF aşamalarını gerçekleştirmek için yeterli oosit sayısını elde etmeyi ve optimal endometriyal gelişimin sağlanmasında önemli bir rol oynar (2). Tedavide gonadotropinlerin kullanılması, overlerin stimülasyonunun temelini oluşturur. $\mathrm{FSH}$, foliküllerin büyümesinin organizatörü iken, LH steroidogenezin ilerlemesinde ve antral folikülün olgunlaşmasında etkilidir(3). IVF tedavilerinde overyan stimülasyonunda LH desteğinin kullanımına ilişkin çok geniş bir bilgi bulunmamaktadır. Bu durum rLH klinik kullanımına ilişkin net bir tablo ortaya çıkartmamaktadır (4). Normal cevaplı IVF hastalarında, gonadotropin-releasing hormone (GnRH) analoğu ile baskılanmış tedavi protokollerinde folükülogenezisin tamamlanmasında LH takviyesi başarılı sonuçlara neden olabilir $(4,5)$. rLH ve rFSH iki gonadotropini bağımsız olarak uygulayarak $\mathrm{KOH}$ protokollerini bireyselleştirme oluşturma fırsatı sunabilir. Böylece LH, oosit maturasyonunda etkili olabileceği gibi IVF tedavilerinde gelişmesinde etkili olabilir. Unutulmaması gereken LH düzeylerinin uygun olmayacak seviyelerde yüksek olması oosit maturasyonu ve folikülogenezis üzerinde olumsuz yan etkileri de oluşturabi$\operatorname{lir}(6,7)$.

Biz çalışmamızda, $\mathrm{KOH}$ sikluslarının indüksiyon protokollerinde $\mathrm{LH}+\mathrm{rFSH}$ ve sadece rFSH kullanımının IVF tedavilerine etkisini karşılaştırmayı amaçladık. Çalışmamızda kliniğimize tedavi için başvuran normal cevaplı hastaların tedavi sonrası elde edilen verileri kullandık. Retrospektif olarak oluşturduğumuz çalışmamızda, tedavide kullanılmış ilaçların oosit sayısı ve kalitesi, fertilizasyon başarısı, iyi kalite embriyo sayıları ve gebelik sonuçları üzerine etkilerini karşılaştırmayı amaçladık.

\section{Materyal ve Metod}

Çalışmamız Sakarya Üniversitesi Tıp Fakültesi girişimsel olmayan etik kurul 15.12.2019 tarih ve 30 sayılı karar izini ile gerçekleştirilmiştir. Çalışmamıza Sakarya Üniversitesi Eğitim ve Araştırma Hastanesi Tüp Bebek Merkezinde 20192020 yılları arasında tedavi gören seksen dokuz infertil çift dahil edildi. Çalışmamıza 20- 40 yaş arası, serum/plazma FSH değerleri 11,2 $\mathrm{mIU} / \mathrm{ml}$ nin altında olan, anti müllerian hormon (AMH) düzeyi $1.1 \mathrm{ng} / \mathrm{ml}$ ve üzerinde olan ovaryan yanıtı normo-responder hasta popülasyonu çalışmaya dahil edildi. Tüm hastalardan işlemler hakkında yazılı bilgilendirilme onam formu alındı.

Çalışmamızda uygulanan stimulasyon protokolü; Grup 1 over stimülasyonunda; rFSH (Gonal-F; Serono Laboratories,) kullanılan ve Grup2; rFSH (Gonal-F)+ rLH (Luveris; Serono Laboratuvarları) kombinasyonu kullanılan hastalar incelemeye alındı. Hastaların iki grubunda da, overyan stimülasyona menstrüel siklusun 2.veya 3. gününde r-FSH (Gonal $\mathrm{F}$, Serono) ile başlanılmış ve $\mathrm{GnRH}$ antagonist protokol uygulanmıştı.

Her iki grubta da; folikül sayısı ve BMI e göre ayarlanarak, başlangıç dozu r-FSH 200-300 IU /gün, subkutan olarak uygulandı. Folüküler büyüme, mevcut duruma göre stimülasyonun 4.gün ve sonrasında, en az günaşırı olacak şekilde transvajinal USG ve serum $E_{2}$ düzeyi ile izlendi. Daha sonra önde gelen folikülün çapı 10 mm'ye ulaştığında günde 0.25 mg cetrorelix (Cetrotide; Asta Medica,) GnRH antagonisti olarak, HCG enjeksiyonuna kadar subkutan yolla uygulandı. Final oosit maturasyonu için, üç büyük folikül ortalama 17 $\mathrm{mm}$ çapa ulaştığı zaman, r-hCG (Ovitrelle, Serono) kullanıldı. Serum $E_{2}$ ve endometrial kalınlık, insan koryonik gonadotropini (HCG) trigger gününde ölçüldü. 35-36 saat sonra transvajinal ultrason eşliğinde oosit pick up işlemi (OPU) yapıldı.

Oositler toplandıktan sonra ICSI işlemi yapıldı. ICSI den 1418 saat sonra fertilizasyonlar kontrol edildi. Döllenen oositler kültüre edildi. Embriyoları 3. veya 5. gün ultrason eşliğinde transfer edildi. Embriyo transferinden sonra luteal faz desteği günde iki aplikatör olmak üzere vajinal progesteron Crinone \% 8 jel (Serono) ile verilerek sağlandı. Embriyo transferinden 14 gün sonra gebelik testi yapıldı. Kimyasal gebelik, embriyo transferinden sonraki günler serum B-hCG seviyeleri $\leq 50 \mathrm{IU} / \mathrm{L}$ olarak kabul edildi.

Yukarıda her iki grupta ortak uygulanan prosedüre ilave olarak sadece Grup 2 de; stimülasyonun 6.-8. günlerinde yapılan folüküler değerlendirme de, serum $E_{2}$ değerine paralel olmayan folükül gelişimi olan ve bir önceki denemelerinde oosit maturasyonu düşük olan vakaların saptanması halinde, stimülasyona r-FSH ile birlikte r-LH 75 IU doz/gün uygulandı.

\section{istatistiksel Analizler}

Tüm istatistiksel değerlendirmeler SPSS 22.0 paket programı (SPSS Inc. ve Lead Tech. Inc. Chicago. ABD) kullanılarak yapıldı. Sürekli verilerin normal dağılıma uygunluğunda Kolmogrov-Smirnov testi kullanıldı. Normal dağılım gösteren numerik verilere Student t-testi, normal dağıl göstermeyen numerik verilerde Mann Whitney $U$ testi, kategorik verilerde ise ki-kare veya Fisher Exact testi uygulandı. Sonuçlar ortalama \pm standart sapma ve yüzde olarak verildi. İstatistiksel anlamlılık için $p<0.05$ kabul edildi.

\section{Bulgular}

Çalışmaya yaş ortalaması $32,14 \pm 4,59$ olan 89 hasta alındı. Bunlardan $35^{\prime}$ i 35 yaş üzeri ve 54 ise 35 yaş altındaydı. ÇaIışmaya dahil edilen hastalar rFSH grubu (Grup 1, $n=40$ ) ve rFSH +rLH grubu (Grup 2, n=49) olmak üzere iki gruba ayrıldı. Her iki gruba ait demografik özellikler Tablo 1'de sunuldu. Total Gonodotropin dozu ve stimülasyon gün sayısı 
açısından iki grup arasında istatistiksel olarak anlamlı düzeyde fark olduğu bulundu.(sırasıyla; $p=0,000 p=0,019$ ). Diğer parametreler her iki grupta da birbirine oldukça yakın ortalamaya sahipti.

Tablo 1. Çalışmaya alınan hastaların demografik özellikleri

\begin{tabular}{|c|c|c|c|}
\hline \multirow[t]{2}{*}{ Parametre } & $\begin{array}{c}\mathrm{rFSH} \\
(\mathrm{n}=40)\end{array}$ & $\begin{array}{c}\mathrm{rFSH}+\mathrm{rLH} \\
(\mathrm{n}=49)\end{array}$ & \multirow{2}{*}{$\mathbf{P}$} \\
\hline & Ortalama \pm SD & Ortalama \pm SD & \\
\hline Kadın yaşı & $30,65 \pm 4,57$ & $31,5 \pm 4,62$ & 0,349 \\
\hline BKi & $24,11 \pm 4,71$ & $24,16 \pm 4,26$ & 0,814 \\
\hline $\begin{array}{l}\text { Total gonadotropin } \mathrm{m} \\
\mathrm{IU} / \mathrm{ml}\end{array}$ & $1857,00 \pm 716,87$ & $2617 \pm 960,23$ & $0,000 *$ \\
\hline Stimülasyon gün sayısı & $9,47 \pm 1,37$ & $10 \pm 1,17$ & 0,019* \\
\hline $\begin{array}{l}\text { Endometrium kalınlığı } \\
(\mathrm{mm})\end{array}$ & $10,09 \pm 1,99$ & $10,06 \pm 2,16$ & 0,566 \\
\hline Hcg günü estradiol pg/ml & $1918,60 \pm 1257,49$ & $2095,34 \pm 1103,49$ & 0,419 \\
\hline Etiyoloji & n (\%) & $\mathrm{n}(\%)$ & \multirow{7}{*}{ - } \\
\hline \multirow{6}{*}{$\begin{array}{l}\text { Endikasyon kadın } \\
\text { Anovulasyon } \\
\text { A çılanamayan infertilite } \\
\text { Endometriozis } \\
\text { Tubal faktör } \\
\text { PCOS } \\
\end{array}$} & $29(72,5)$ & $42(84)$ & \\
\hline & $4(10)$ & $11(22)$ & \\
\hline & $16(40)$ & $16(32)$ & \\
\hline & $3(7,5)$ & $5(10)$ & \\
\hline & $1(2,5)$ & $4(8)$ & \\
\hline & $5(12,5)$ & $8(16)$ & \\
\hline Endikasyon erkek & $29(72,5)$ & $28(56)$ & $\begin{array}{l}- \\
- \\
-\end{array}$ \\
\hline
\end{tabular}

Veriler ortalama, standart sapma ve yüzde olarak verildi. SD: Standart sapma, n: Sayı ${ }^{*} p<0.05$ anlamlı olarak kabul edildi. BKi (Beden Kitle indeksi).PCOS(Polikistik Over Sendromu).

Çalışma gruplarında 35 yaş üzeri hastaların embriyolojik ve stimülasyon özellikleri açısından karşılaştırılması Tablo 2'de sunulmuştur. Ortalama MI, fertilize oosit sayısı ve fertilizasyon oranı Grup 2'de daha yüksekti. Ancak gruplara arasında istatistiksel açıdan anlamalı farklılık bulunmadı ( $p>0.05$. Gradel embriyo, kryo yapılan embriyo sayısı, toplanan oosit sayısı ve beklenen oosit sayısı ortalama değerleri grup 1'de daha yüksek olmasına rağmen gruplar arasında anlamlı bir fark bulunmadı $(p>0,05)$ (Tablo 2 ).

Tablo 2. Çalışmaya alınan 35 yaş üstü hastalara ait embriyolojik ve stimülasyon özelliklerinin karşılaştırılması

\begin{tabular}{|c|c|c|c|}
\hline \multirow[t]{2}{*}{ Parametre } & $\begin{array}{c}\mathrm{rFSH} \\
(\mathrm{n}=13)\end{array}$ & $\begin{array}{c}\mathrm{rFSH}+\mathrm{rLH} \\
(\mathrm{n}=22)\end{array}$ & \multirow{2}{*}{$\mathbf{P}$} \\
\hline & Ortalama \pm SD & Ortalama $\pm S D$ & \\
\hline MI oosit sayısı & $0,92 \pm 1,55$ & $1,36 \pm 1,36$ & 0,890 \\
\hline MII oosit sayısı & $5,53 \pm 3,84$ & $5,45 \pm 4,21$ & 0,172 \\
\hline Gv oosit sayısı & $1,2 \pm 1,5$ & $0,4 \pm 0,6$ & 0,139 \\
\hline Fertilize oosit sayısı & $4,76 \pm 4,32$ & $4,86 \pm 4,24$ & 0,756 \\
\hline Total oosit sayısı & $7,61 \pm 5,63$ & $7,27 \pm 5,47$ & 0,103 \\
\hline Fertilizasyon oranı & $64,69 \pm 16,64$ & $76,09 \pm 23,82$ & 0,396 \\
\hline Grade 1 & $1,76 \pm 1,92$ & $2,22 \pm 2,09$ & 0,471 \\
\hline Kryo yapılan embriyo_sayısı & $1,92 \pm 3,42$ & $2,09 \pm 3,26$ & 0,784 \\
\hline Beklenen oosit sayısı & $7,07 \pm 3,59$ & $7,09 \pm 4,63$ & 0,986 \\
\hline Toplanan oosit sayısı & $7,61 \pm 5,63$ & $7,22 \pm 5,36$ & 0,890 \\
\hline
\end{tabular}

Tüm veriler ortalama ve standart sapma olarak verildi. SD: Standart sapma, MII:Metafaz II, MI:Metafaz I, GV:germinal vezikül, n: Sayı. . $p<0.05$ anlamlı olarak kabul edildi.

Çalışma gruplarında 35 yaş altı hastaların embriyolojik ve stimülasyon özellikleri açısından karşılaştırılması Tablo 3'de sunulmuştur. Tabloda sunulan tüm parametrelerin ortalama değerleri grup 2'de daha yüksek olduğu bulunmasına rağmen gruplar arasında istatistiksel açıdan anlamalı farklılık yoktu ( $p>0.05$ ). (Tablo 3)
35 yaş altı ve üstü $r$-FSH ve $r-F S H+r$-LH tedavi protokolleri arasında istatistiksel olarak anlamlı farklar görülmedi. İki grup arasında gebelik sonuçları açısından farklılık görülmedi (Şekil 1).

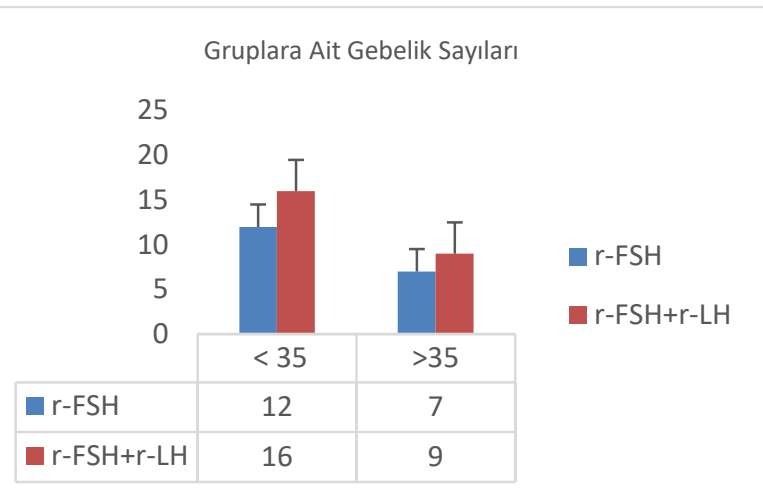

Şekil 1. Gruplar arası gebelik sayıları. Gruplar arasında r-FSH ve $r-F S H+r-L H$ tedavi gruplarının yaşa bağlı gebelik sonuçları arasında istatistiksel olarak anlamlı bir fark görülmedi. $P$ $<0.05$ anlamlı olarak kabul edildi.

Tablo 3. Çalışmaya alınan 35 yaş altı hastalara ait embriyolojik ve stimülasyon özelliklerinin karşılaştırılması

\begin{tabular}{|c|c|c|c|}
\hline \multirow[t]{2}{*}{ Parametre } & $\begin{array}{l}\mathrm{rFSH} \\
(\mathrm{n}=27)\end{array}$ & $\begin{array}{c}\text { rFSH+rLH } \\
(n=27)\end{array}$ & \multirow{2}{*}{$\mathbf{P}$} \\
\hline & Ortalama \pm SD & Ortalama $\pm S D$ & \\
\hline MI oosit sayısı & $1,37 \pm 1,30$ & $1,51 \pm 1,25$ &, 579 \\
\hline MII oosit sayısı & $6,48 \pm 4,08$ & $7,88 \pm 5,52$ & ,292 \\
\hline Gv oosit sayısı & $1,66 \pm 1,51$ & $2,03 \pm 2,29$ & 677 \\
\hline Fertilize oosit sayısı & $5,62 \pm 3,67$ & $7,11 \pm 5,84$ & ,308 \\
\hline Total oosit_sayısı & $9,51 \pm 5,85$ & $11,48 \pm 7,72$ & ,344 \\
\hline Fertilizasyon oranı & $76,51 \pm 19,16$ & $79,11 \pm 21,53$ &, 579 \\
\hline Grade I embriyo sayısı & $2,96 \pm 2,42$ & $4,33 \pm 5,63$ & ,241 \\
\hline Kryo yapılan embriyo sayısı & $3,11 \pm 3,40$ & $4,74 \pm 5,28$ & 154 \\
\hline Beklenen oosit sayısı & $9,03 \pm 4,6$ & $9,77 \pm 5,04$ & ,577 \\
\hline Toplanan oosit sayısı & $9,51 \pm 5,85$ & $11,14 \pm 8,08$ & 400 \\
\hline
\end{tabular}

Tüm veriler ortalama ve standart sapma olarak verildi. SD: Standart sapma, MII: Metafaz II , MI: Metafaz I, GV: germinal vezikül , n: Sayı. $p<0.05$ anlamlı olarak kabul edildi.

\section{Tartışma}

İki hücreye, iki gonadotropin teorisine göre folikülogenez için hem FSH hem de LH gereklidir. FSH, aromataz enzim aktivitesini uyararak ve granüloza hücrelerinde $\mathrm{LH}$ reseptörlerinin eksprese olmasına izin vererek folüküler gelişimde önemli bir rol oynar (8). Folüküler gelişimin geç evrelerinde granüloza hücrelerinin LH uyarımına yanıt verdiği ve $\mathrm{LH}^{\prime}$ In hem teka hem de granüloza hücreleri üzerindeki etkilerini gösterdiği kabul edilmektedir(9). Aromataz enzim aktivitesinin uyarılması gibi pek çok fizyolojik etkinin folüküler dönemin ortalarında granüloza hücrelerinde LH reseptörlerinin ortaya çıkmasıyla desteklendiği bilinmektedir (10). Özellikle ileri yaş gibi, bazı hasta popülasyonlarında, $\mathrm{GnRH}$ agonistlerinin kullanımının, endojen LH aktivitesinin baskılanmasına yol açtığı ve bu durumun da folüküler olgunlaşma için gerekli LH seviyesinin eşik değerin altına düşürdüğü düşünülmektedir. Bu hastaların eksojen LH kullanımından fayda görebileceği varsayılmaktadır (11). 
Erken folüküler fazda LH' ın etkin olmasından dolayı folükül gelişiminde istenmeyen etkiler görüldüğünden, r-LH folüküler fazın geç döneminde kullanılmaya başlanmıştır. r-LH' ın başlangıcı, birçok çalışmada genellikle stimülasyonun altıncı ve sekizinci günü arasında kabul edilir. Yapılan bir çalışmada en büyük folikül 14 mm çapa ulaştığında rLH uygulamasına başlandığı bildirilmiştir (12).

Over hiperstimülasyonunda LH takviyesi tartışmalı bir konu olmaya devam etmektedir. Konu hakkındaki tartışma, LH aktivitesi içermeyen rFSH preparatlarının varlığı ve endojen LH aktivitesinin baskılanmasına neden olan GnRH agonistlerinin klinik kullanımı artmasından kaynaklanmaktadır. Hastaların yaklaşık \%10-12' sinde mevcut $\mathrm{KOH}$ stimülasyon protokollerine yanıt vermez. Bu durumun, LH eksikliğine bağlı olduğu düşünülmektedir (13).

IVF için yumurtalık stimülasyonu sırasında LH takviyesi, birçok IVF merkezinde tedavi protokolünün bir parçasıdır. Bunun yanı sıra asıl soru hangi hasta gruplarının LH takviyesinden fayda görebileceğidir (14). Bizim çalışmamızda, orta folüküler fazda r-LH eklentisinin, tüm yaş grupları dikkate alındığında gruplar arasında total oosit sayısı ve MII oosit sayısı gibi $\mathrm{KOH}$ tedavilerinde hedeflenen parametreler üzerine istatistiksel olarak anlamlı farklar gözlenmedi.

Ayrıca, LH desteğinin tüm yaş gruplarında iyi kaliteli embriyo sayısı ve gebelik oranları üzerinede istatistiksel bir etkisi olmadığı görüldü. Çalışmamızda, 35 yaş ve üstü hasta alt grubu değerlendirildiğinde, stimülasyon protokolüne 75 IU/gün rLH eklenmesinin, sonuçlara olumlu yönde etkilemesine rağmen istatistiksel olarak anlamlı farklara neden olmadığı görüldü. Yine gruplar arasında gebelik oranları karşılaştırıldığında sonuçlar arasında istatiksel anlamlı bir fark görülmese de, gebelik oranlarının rLH eklentisi olan gruplarda daha yüksek olduğu görüldü. Bunun hasta sayımızın az olmasından kaynaklanabileceğini düşünmekteyiz. Literatürde çalışmamıza benzer ve farklı sonuçlar veren araştırmalar bulunmaktadır.

De Placido (14) tarafından yayınlanan bir çalışmada, eksojen rFSH uygulamasına zayıf yanıt veren normoovulatuar normogonadotropik hastalarda stimülasyon protokolüne FSH ve LH içeren hMG'nin (1/1 oranında) eklenmesi IVF sonuçlarını pozitif etkilediğini bildirmişlerdir. Yapılan bir çalışmada, 35 yaş üstü 121 hastayı içeren bir çalışmada, protokole rLH eklenmesinin, hipofiz baskılanmasını takiben FSH ile uyarılan hastalarda metafaz II oositleri ve klinik gebelik oranlarında anlamlı bir fark yaratmadığını bildirdi. Ayrıca aynı grup 35 yaş altı gruplar arasında anlamlı bir fark olmadığını da bildirmişlerdir (14). Başka bir çalışmada, rFSH ve rFSH + rLH protkollerini göreceli performansının karşılaştırmalı olarak değerlendirdikleri metanalizde, genel popülasyondaki iki tedavi arasında alınan oosit sayısında bir fark bulmadığını, ancak rFSH / rLH'nin kullanıldığı zayıf yanıt veren döngülerde daha yüksek sayıda oosit elde edildiğini bildirmişlerdir (15).

Humaidan(16), $231 \mathrm{KOH}$ siklusu üzerinde yapılan bir çalışmada rLH takviyesi uygulanan 35 yaş üstü hastalarda ista- tistiksel olarak anlamlı yüksek implantasyon ve klinik gebelik oranları bildirmişlerdir $(16)$. Matorras ve Bosch $(17,18)$, tarafından yapılan benzer çalışmalarda; over hiperstimülasyon protokolüne LH desteği eklendiğinde 35 yaşın üzerindeki hastaların daha iyi implantasyon ve devam eden gebelik oranlarına sahip olduklarını bildirmişlerdir $(17,18)$. IVF tedavilerinde, LH takviyesi üzerine fikir birliği, over stimülasyonuna zayıf yanıt ve suboptimal over yanıtı öyküsü olan hastalarda fayda sağlayacağı yönündedir (19). 137 hastayı içeren yakın zamanda yayınlanan bir çalışmada ise rLH ilavesinin, GnRH agonist protokolü sırasında rFSH ile ovülasyon indüksiyona sonuçların düzeltilmesi için bir seçenek olarak kullanılabileceği bildirilmiştir (20). Humadian ve arkadaşları (2017) yaptıkları çalışmada, 939 poor responder hastada rFSH ile rFSH+rLH protokollerini karşılaştırdıklarında, oosit sayıları arasında bir farklılık görmemelerine rağmen, total gebelik ve devam eden gebelik oranlarının rFSH+rLH grubunda daha yüksek olduğunu bildirmişlerdir. rLH ' In poor responder hasta grubunda tedavide kullanılmasının başarıyı arttıracağını bildirmişlerdir(21).

Çalışmamızda $\mathrm{KOH}$ un orta folüküler fazında r-LH takviyesinin istatistiksel olarak anlamlı farklar oluşturmamasına rağmen, tüm yaş gruplarında genel olarak oosit ve Gradel embriyo sayılarını tedavide kullanılmayan fakat dondurulan embriyo sayılarını arttırdığı görülmektedir. Ayrıca IVF_ICSI uygulamalarında kullanılan kontrollü ovaryan stimülasyon protokollerine, r-LH ilavesi yapmak için, kadın yaşının tek başına, yeterli bir kriter olmadığı görülmektedir.

Hasta sayısının daha fazla olduğu randomize kontrollü çalışmalarının yapılması gerektiği kanaatindeyiz. Çalışmamız retrospektif bir çalışma olduğundan bazı kısıtlamalarımız oldu. Erkek faktörünün çok görülmesi, beklenen oositten fazla veya az toplanmasıda IVF tedavisi sonuçlarımızı etkilediğini düşünmekteyiz.

Etik onam: Çalışmamı Sakarya Üniversitesi Tıp Fakültesi girişimsel olmayan etik kurul 15.12.2019 tarih ve 30 sayılı karar izini ile gerçekleştirilmiştir.

\section{Yazar Katkıları:}

Konsept: Ö.B., N.A.

Literatür Tarama: Ö.B., N.A.

Tasarım: Ö.B., S.D.

Veri toplama: Ö.B., S.D.

Analiz ve yorum: Ö.B., M.S.B., A.S.C.

Makale yazımı: Ö.B., N.A., M.S.B., A.S.C.

Eleştirel incelenmesi: Ö.B., N.A., M.S.B., A.S.C.

Çıkar Çatışması Yazarlar çıkar çatışması beyan etmemişlerdir. Finansal Destek: Yazarlar finansal destek beyan etmemişlerdir.

\section{Kaynaklar}

1. Filicori M, Cognigni GE, Taraborrelli S, at.all.. Low-dose human chorionic gonadotropin therapy can improve sensitivity to exogenous follicle-stimulating hormone in patients with secondary amenorrhea. Fertil Steril. 1999;72(6):1118-1120.

2. Mennini FS, Marcellusi A, Viti R, et al. Probabilistic cost-effectiveness analysis of controlled ovarian stimulation with 
recombinant FSH plus recombinant $\mathrm{LH}$ vs. human menopausal gonadotropin for women undergoing IVF. Reprod Biol Endocrinol. 2018;16(1):68.

3. Leão Rde B, Esteves SC. Gonadotropin therapy in assisted reproduction: an evolutionary perspective from biologics to biotech. Clinics (Sao Paulo). 2014;69(4):279-293.

4. Fleming R, Lloyd F, Herbert M, Fenwick J, Griffiths T, Murdoch $A$. Effects of profound suppression of luteinizing hormone during ovarian stimulation on follicular activity, oocyte and embryo function in cycles stimulated with purified follicle stimulating hormone. Hum Reprod. 1998;13(7):1788-1792.

5. Hillier SG. Gonadotropic control of ovarian follicular growth and development. Mol Cell Endocrinol. 2001;179(1-2):3946.

6. Zeleznik AJ. Follicle selection in primates: "many are called but few are chosen". Biol Reprod. 2001;65(3):655-659.

7. Shoham Z. The clinical therapeutic window for luteinizing hormone in controlled ovarian stimulation. Fertil Steril. 2002;77(6):1170-1177.

8. Burgués $S$. The effectiveness and safety of recombinant human LH to support follicular development induced by recombinant human FSH in WHO group I anovulation: evidence from a multicentre study in Spain. Hum Reprod. 2001;16(12):2525-2532.

9. Schoot DC, Coelingh Bennink HJ, Mannaerts BM, Lamberts SW, Bouchard P, Fauser BC. Human recombinant follicle-stimulating hormone induces growth of preovulatory follicles without concomitant increase in androgen and estrogen biosynthesis in a woman with isolated gonadotropin deficiency. J Clin Endocrinol Metab. 1992;74(6):1471-1473.

10. Fábregues F, Creus M, Peñarrubia J, Manau D, Vanrell JA, Balasch J. Effects of recombinant human luteinizing hormone supplementation on ovarian stimulation and the implantation rate in down-regulated women of advanced reproductive age. Fertility and sterility. 2006;85(4):925-931.

11. De Placido G, Mollo A, Alviggi C, et al. Rescue of IVF cycles by HMG in pituitary down-regulated normogonadotrophic young women characterized by a poor initial response to recombinant FSH. Hum Reprod. 2001;16(9):1875-1879.

12. Tarlatzis B, Tavmergen E, Szamatowicz M, et al. The use of recombinant human $\mathrm{LH}$ (lutropin alfa) in the late stimulation phase of assisted reproduction cycles: a double-blind, randomized, prospective study. Human Reproduction. 2005;21(1):90-94.

13. Hill MJ, Levens ED, Levy G, et al. The use of recombinant luteinizing hormone in patients undergoing assisted reproductive techniques with advanced reproductive age: a systematic review and meta-analysis. Fertil Steril. 2012;97(5):11081114.e1101.

14. Marrs R, Meldrum D, Muasher S, Schoolcraft W, Werlin L, Kelly E. Randomized trial to compare the effect of recombinant human FSH (follitropin alfa) with or without recombinant human LH in women undergoing assisted reproduction treatment. Reprod Biomed Online. 2004;8(2):175-182.

15. Vuong TN, Phung HT, Ho MT. Recombinant follicle-stimulating hormone and recombinant luteinizing hormone versus recombinant follicle-stimulating hormone alone during $\mathrm{GnRH}$ antagonist ovarian stimulation in patients aged $\geq 35$ years: a randomized controlled trial. Hum Reprod. 2015;30(5):1188-1195.

16. Lehert P, Schertz JC, Ezcurra D. Recombinant human follicle- stimulating hormone produces more oocytes with a lower total dose per cycle in assisted reproductive technologies compared with highly purified human menopausal gonadotrophin: a meta-analysis. Reprod Biol Endocrinol. 2010;8:112.

17. Bosch E, Labarta E, Crespo J, Simón C, Remohí J, Pellicer A. Impact of luteinizing hormone administration on gonadotropin-releasing hormone antagonist cycles: an age-adjusted analysis. Fertil Steril. 2011;95(3):1031-1036.

18. Humaidan $P$, Bungum $M$, Bungum $L$, Yding Andersen C. Effects of recombinant LH supplementation in women undergoing assisted reproduction with GnRH agonist down-regulation and stimulation with recombinant FSH: an opening study. Reprod Biomed Online. 2004;8(6):635-643.

19. Matorras R, Prieto B, Exposito A, et al. Mid-follicular LH supplementation in women aged 35-39 years undergoing ICSI cycles: a randomized controlled study. Reprod Biomed Online. 2009;19(6):879-887.

20. Wong PC, Qiao J, Ho C, et al. Current opinion on use of luteinizing hormone supplementation in assisted reproduction therapy: an Asian perspective. Reprod Biomed Online. 2011;23(1):81-90.

21. Humaidan P., Chin W., Rogoff,D., D'Hooghe,T., Longobardi S., Hubbard J., at al. Efficacy and safety of follitropin alfa/lutropin alfa in ART: a randomized controlled trial in poor ovarian responders. Human Reproduction, Vol.32, No.3 pp. 544-555, 2017 